\title{
Digitalized Co-production: Using Volunteers as First Responders
}

Sofie Pilemalm

The self-archived postprint version of this conference paper is available at Linköping University Institutional Repository (DiVA):

http:// urn.kb.se/ resolve?urn=urn:nbn:se:liu:diva-179286

N.B.: When citing this work, cite the original publication.

Pilemalm, S., (2021), Digitalized Co-production: Using Volunteers as First Responders, 2021 Eighth International Conference on eDemocracy \& eGovernment (ICEDEG), pp 25-32.

https:// doi.org/ 10.1109/ ICEDEG52154.2021.9530994. ISBN: 978-1-6654-2513-1

Original publication available at:

https:// doi.org/ 10.1109/ICEDEG52154.2021.9530994

Copyright:

Institute of Electrical and Electronics Engineers (IEEE) http://www.ieee.org/index.html

(C2021 IEEE. Personal use of this material is permitted. However, permission to reprint/republish this material for advertising or promotional purposes or for creating new collective works for resale or redistribution to servers or lists, or to reuse any copyrighted component of this work in other works must be obtained from the IEEE. 


\title{
Digitalized Co-production: Using Volunteers as First Responders
}

\author{
Sofie Pilemalm \\ Dept. of Management and Engineering, Dept of Information Systems \\ Linköping university, University of Agder \\ Linköping, Sweden, Kristiansand, Norway \\ sofie.pilemalm@liu.se
}

\begin{abstract}
This study explores digitalized co-production using citizens as volunteer first responders in cities with as specific focus on socially vulnerable areas. It shows that volunteers can make a major difference, e.g., saving lives, administering CPR and extinguishing fires. The ICT artefact is crucial to the coproduction by allowing volunteers to be dispatched through their own mobile phones and providing geographical positioning. Identified challenges include to make individual engagement collective, to reduce the risk of the volunteers being exposed to dangerous situations and to further calibration of the ICT. The study argues for digitalization as an enabler of new co-production initiatives, with basic mobile ICT artefacts as the starting point, and that local public sector initiatives aimed to improve inclusion, safety and first response can have positive consequences both nationally and globally. It also contributes to a merging of research perspectives from public administration and information systems, with reference to digitalized co-production.
\end{abstract}

Keywords-co-production, ICT, digitalization

\section{INTRODUCTION}

There is this an increasing awareness of the potential of digitalization to deliver benefits to public service delivery including interaction with civil citizens [1]. In co-production, citizens become part of the conception, design, steering, and management of public services [2]. Co-production does not explicitly presume digitalization. However, some recent studies reveal how digitalization and information and communication technology (ICT) enable and transform citizen engagement and co-production (e.g. [3], [4]). Related studies often embrace such aspects as open data, service innovation, e-government, smart cities, and urban governance, using sophisticated technologies "and sometimes urban living labs" (e.g. [5], [6], [7], [8].

In emergency management professional response organizations in many countries experience resource constraints. This affects, e.g., excluded urban areas and suburbs, where societal structures are often deemed absent and that are sometimes characterized by increasing criminality [9], [10]. This study focuses on an initiative using citizen volunteers as first responders in collaboration with the municipal fire services in the environs of Stockholm, the capital of Sweden. The initiative is aimed at improving safety aspects and enhancing the effectiveness of first response. The initiative is studied here as an example of ICT-enabled, i.e., digitalized co-production using basic mobile app solutions. To the best of our knowledge, using citizen volunteers as first responders in long-term engagement collaborations with a focus on frequent accidents is innovative, and somewhat pioneering from a global perspective. Thereby, it has the ability to create positive long-term societal consequences, if disseminated at national macro-level and internationally.

\section{A. Study aim and objectives}

The study aim is to explore the concept of engaging civil citizens as first responders with specific focus on cities and socially vulnerable areas. The objectives include:

- Describing recruitment and tasks of citizen first responders and identifying key factors for implementing the concept in terms of benefits, challenges, and needs.

- Identifying the distinct features of the ICT artefact as a catalyst for the co-production initiative.

This study is a continuation of a previous study of the initiative's early phases, involving only two citizen volunteers in excluded areas, together with the rescue services perspectives. This study takes the civil citizen perspective one year later and adds data from additional volunteer first responders, and respondents from the fire association. It thus includes additional results and discussion on how digitalized co-production take various forms in various parts of the municipality. The intended audience is researchers and practitioners in public-sector transformation, digitalization, coproduction and citizen engagement with particular relevance to emergency management. It should also have international relevance because co-production is growing globally, as are emergency response challenges.

\section{THEORY AND BACKGROUND}

Co-production is first related to digitalization, and ICT, followed by a brief description of the studied initiative.

\section{A. Digitalized Co-production}

Co-production can be defined as a practice in which citizens are involved in the creation of public policies and services. It may be contrasted with a transaction-based method of service 
delivery in which citizens consume public services that are provided by governments. In co-production, citizens are not only consulted, but are part of services' design, steering, and management [2], [11]. Co-production stems mainly from public administration and does not explicitly presume digitalization or an ICT artefact. However, over the past few years, several studies have emphasized the increasing role of digital technologies, using terms such as "ICT as an enabler", "co-production through ICT", and "ICT facilitated coproduction" (e.g. [3], [4]).

Most contemporary studies on co-production in western societies tend to focus on areas such as social media, open data, service innovation, crowdsourcing, smart cities, and urban governance, often addressing broad and comparatively well-off citizen groups (e.g. [5], [6], [8], [12]). Many studies describe projects driven by (urban) living labs that are integrated through the co-creation, experimentation, and evaluation of innovative ideas, scenarios, concepts, and related technological artefacts in real-life cases. Often, they assume rather sophisticated technologies, such as augmented reality, IoT, or virtual reality (e.g. [7], [8], [13]). At the same time, several studies have highlighted that disadvantaged people, such as ethnic minorities, the less educated, and those in lower socio-economic situations, are less willing to participate in co-production (e.g. [14]).

In many western countries, socio-economic gaps and exclusion are growing at a rapid pace. Increasing urbanization, in general and also associated with recent migration streams, have resulted in many suburbs or urban sub-areas that are characterized by segregation. Here, residents often experience insecurity and a lack of trust in the authorities and perceive themselves as having few opportunities for inclusion in society, to influence their environment or their own lives. Unemployment is usually higher than average, resulting in low socio-economic status, and recruitment to criminality is correspondingly growing, especially among young people [9]. To date there have been few studies that focus (digitalized) coproduction of urban excluded areas in western countries. There are exceptions, such as [15], who, in a study in Belgium, found that co-production in community development projects in derelict neighborhoods may lead to more inclusion, and empowerment. However, most studies involving excluded groups focus either on the perceived inequality of individuals due to their youth, gender, disability, or ethnicity (e.g. [16]). Alternatively, they take place in poor or developing countries in (e.g. [17], [18], far away from smart cities and sophisticated, technology-driven labs.

Thus, we believe that there is a need to explore coproduction initiatives in general and in excluded urban areas in specific, to connect them explicitly to the ongoing digitalization and suggest ways forward. Emergency response makes an interesting case, because it is ultimately about saving lives and minimizing human suffering. Also, local initiatives enabled by basic mobile ICT solutions, have the potential to provide a basis for regional, national, and global changes in terms of thinking about and implementing digitalized co-production. From a wider perspective, they open up opportunities for interesting mergers of research disciplines. The way in which public administration and information systems (IS) research can complement each other has recently been pointed out in relation to government and a public sector undergoing change [19], [20], [21]. We will relate this overall discussion to co-production.

\section{B. Study Context}

In this study, emergency response refers to actors, technologies, procedures, and rules that are involved in response to emergencies such as traffic accidents, fires, and medical situations. Citizen volunteerism initially expanded rapidly within large-scale crisis management. Over the past decade, organizing volunteers as first responders has also gained some attention in relation to commonly occurring smaller accidents [22]. In Sweden, various co-production initiatives have taken place over the past decade to improve efficiency by the involvement of volunteers in day-to-day first response, in collaboration with the professional operative response organizations (fire services, ambulance services, and the Public Safety Answering Point). The idea was first applied in remote, sparsely populated areas in northern Sweden, where civil citizens are often much closer to an incident site than the response organizations and will likely arrive faster [23]. More recently, the initiative has spread to cities and socially vulnerable sub-areas in parts of the country.

The initiative is located outside the capital of Stockholm. Stockholm has a population of about ten million people, when the surrounding municipalities are included, and this has increased rapidly in recent decades, due to both urbanization and refugee immigration during 2015-2016. The studied initiative takes place in a municipality just outside Stockholm with about 100000 inhabitants. Here, the major Swedish Fire Response Association has set up an initiative that involves direct collaboration with citizen volunteers. In the study we include, first, both the central part of the municipality (excluded area) and another part of the municipality, that is close to the Stockholm archipelago. We studied the initiative 2019-2020 for a period of 18 months.

\section{METHODS}

The specific study design is an explorative case study [24]. in that it views volunteer co-production in emergency response as the overall phenomenon being studied.

\section{A. Interviews and Focus Groups}

The research was mainly based individual interviews and focus groups. In semi-structured interviews, a template or set of themes is usually applied, but no strict adherence to the template is required and respondents can make other associations during the interview. Focus groups work similarly but enable intra-group dynamics and collective views on a particular phenomenon [24]. A combination of snowball sampling and a convenience sample approach [25] was used. This is because the initiative was emerging and undergoing expansion, but also because it is based on the voluntary 
engagement of citizens, who are usually only accessible during the evenings. For the interviews, snowball sampling was applied because it was deemed important to interview those volunteers who had responded to several alerts. For the focus groups, convenience sampling was deemed the only possible way to gather people at the same time, and the fire services project leader invited volunteers to a focus group meeting. The researchers also took part in Facebook (FB) groups related to the initiative, to recruit potential interview respondents. Of course, the sampling strategies may have affected the study results, which we will discuss later.

First, five interviews with respondents from the central part of the municipality were conducted. Of these, two respondents are also included in the previous study that took place during the initial project phase and mainly embraced the perspective of the Fire Response Association [26]. Two focus group were then conducted in parallel. One included the fire services project leader and two firefighters who worked the night shift at the fire station to assess the initiative's progress in the central municipality and need for further development. The other included five volunteers in a community outside the central part of the municipality. Two additional interviews were finally held with other volunteers in the same community, to reach a sufficient number of respondents. The data collection for this study was thus complemented with a total of eleven civil citizens, and with the Fire Association's perspective one year later. The respondents are summarized in Table I.

TABLE 1.

\begin{tabular}{|l|l|l|c|}
\hline $\begin{array}{l}\text { Central } \\
\text { municipality }\end{array}$ & $\begin{array}{l}\text { Interviews with } \\
\text { volunteers (5) }\end{array}$ & $\begin{array}{l}\text { Focus group with Project } \\
\text { Leader + Firefighters (3) }\end{array}$ & 8 \\
\hline $\begin{array}{l}\text { Smaller } \\
\text { community }\end{array}$ & $\begin{array}{l}\text { Interviews with } \\
\text { volunteers (3) }\end{array}$ & $\begin{array}{l}\text { Focus group with volunteers } \\
(5)\end{array}$ & 8 \\
\hline $\begin{array}{l}\text { Total number of } \\
\text { respondents }\end{array}$ & & $\mathbf{1 6}$ \\
\hline
\end{tabular}

Each interview lasted for about one hour and the focus groups for about two hours. The same basic templates were applied but adapted depending on whether someone from the fire services or a volunteer was being interviewed. The questions concerned the initiatives' progress over time, identified benefits, success factors, challenges, and needs, both as to the collaboration itself and the ICT support used for dispatch. Themes and questions were also used flexibly depending on whether the volunteers' area belonging. All data were audio-recorded and transcribed. For the analysis, a thematic approach was used [26], clustering data into overall themes, with a focus on development, as exemplified in the questions above. Two researchers, performed the data collection together, including the construction of interview templates, and the data analysis. The focus groups were carried out together, while one of the researchers carried out the individual interviews.

\section{RESULTS}

The identified themes are presented. A brief comparison between the two areas will be integrated throughout the section.

\section{A. Using Volunteers as First Responders}

The fire association recruits citizens as first responders. They live in various parts of the municipality and many in socio-economically excluded areas. The volunteers are provided with one day of basic training in such tasks as first aid, heart-and-lung rescue (CPR), extinguishing small fires, and acting in single-vehicle traffic accidents. They also receive a backpack containing a first-aid kit, reflective vests, pocket masks, and hand-held fire extinguishers. The idea is not to have the volunteers replace the professional response organizations, but to carry out first response while waiting for the professionals to arrive. Acting on the alert is always voluntary.

The central part of the municipality is of larger size (about 50000 inhabitants) with frequent alerts, while a more remote community may have about 3500 inhabitants and comparatively few alerts. In the former, the aims of the initiative are twofold, including a more efficient response and the desire to create a sense of presence, security, and social relations, decreasing the incidence of intentional fires (mostly in cars), assaults, and vandalism. In the smaller communities, inclusion relates rather to geographical distance which, together with scarce response resources, has led to inhabitants not being sufficiently protected as stated by the Swedish Civil Protection Act [27]. The ambulance, rescue, and police services are situated too far away, which can be fatal in, e.g., a case of heart failure. In the central parts, the response efficiency aspect is also deemed important, but here the overall response times for professional response organizations are short in comparison.

\section{B. Recruitment of Volunteers}

In the socially vulnerable central areas, the responders from the fire services in the focus group describe how they have used local-interest associations, the municipality and related realestate companies for recruitment campaigns. The initial interest was much higher than they expected. The project leader provided an example in which an entire Syrian Orthodox association of about 200 women signed up. However, showing up initially did not necessarily imply engagement over time. After about a year, the fire services decided to carry out information campaigns at the same time as doing home visits (home visits are usually carried out for fire preventive causes). In the more remote municipality communities, social media, information campaigns and local-interest associations were similarly used. The interest was just as high in these areas, with the major difference being that interest actually led to numerous volunteers showing up at training sessions, becoming first responders, and acting on alerts.

\section{Digitalization and ICT: Dispatching of Volunteers}

The citizen volunteers are dispatched to the following types of emergency: outdoor fires (e.g. vehicle), fires in buildings, heart failure, single-vehicle traffic accidents, and drownings. The emergency should not be risky for them (e.g. uncontrolled fires or a shooting), and they should be able to carry out first response using the kit in their small equipment backpack. The volunteers are dispatched by a commercial app installed on their own android phones. Their mobile phone GPS functions 
are connected to the fire services' back-office system for handling incoming alerts., The volunteers will receive an alert with a distinctive signal if they are within a radius of 5 kilometers of the emergency. The app displays the position coordinates, the address (road, but not specific number), municipality area and type of emergency, giving basic information such as number of casualties and their status (Figure 1). It also includes a map, and when the alert is triggered a red button appears on the map, indicating the emergency site. Through this button, the volunteers can also communicate with the rescue services and each other and provide updated information about the emergency through a basic chat function. It is the fire services' back-office systems that provide the GPS coordinates, the addresses, and the information about the emergency. Therefore, volunteers receive the same basic information as professional first responders. The alerts are manually overheard by an operator at the Public Safety Answering Point, i.e., the process is not entirely automated.

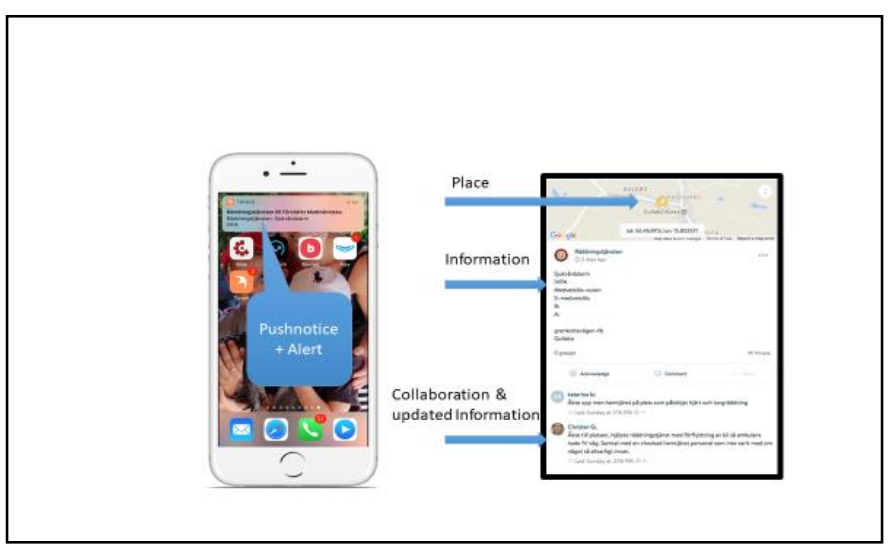

Fig. 1. Dispatching of volunteers through the app. The type of incident here is a single-vehicle traffic accident in which the victim is unconscious.

Apart from dispatching, each sub-area has its own private FB group. Here, volunteers can communicate with each other and the rescue services after an emergency to discuss what happened, what went well, what went less well, and the functionality of the app. Also, upcoming information campaigns and exercises are announced here.

\section{First Response Tasks}

The volunteers perform a range of tasks at the emergency site, but those reported as most frequent are somewhat different between areas, according to the focus group with the fire association. In excluded central urban areas, the most common types of task as expressed by the interview volunteers are extinguishing small fires, checking whether the fire has spread and if so informing the fire services, translating information, backing bystanders and keeping them at a distance when the professional response organizations arrive. They have also acted in some single-vehicle traffic accidents with basic firstaid tasks (band aids, stopping minor bleeding) and providing comfort, and on heart-failure alarms:
Fires in buildings, cars, and on ground. Drownings and accidents with diverse vehicles...heart failures, but these alerts are currently put on hold due to the Corona-situation. When I get there, the important thing is to have an overall view of the situation... When the professionals arrive, I might calm chocked relatives, direct the traffic... (volunteer, central municipality, interview).

In the smaller municipality areas, the emergencies most reported are single-vehicle traffic accidents and heart failures, with the corresponding tasks relating mainly to CPR and first aid. All volunteers receive a debriefing from fire service personnel immediately after a response operation, but no formal follow-ups. But, as stated by one of the volunteers in the interviews, "the fire station is always open". Also, the project leader and the app supplier are deemed easily accessible via the FB group. The volunteers are collectively insured by the fire association.

\section{E. Percieved Benefits}

As to the volunteers in the central municipality excluded areas, about a year after the initiative began, there is substantial engagement on some of the volunteers. Also, when something does happen, volunteers may arrive before the fire services, and a single first response can make a major difference:

\footnotetext{
Was at home, 200 meters from me, went there, they're screaming from the balcony that he's died. Seven floors up. He was on the floor, not breathing, I started CPR. He comes back, starts breathing. Two minutes later, the ambulance arrives. He is alive. (volunteer, central municipality, interview)
}

Over time it has been shown to be crucial that volunteers who are active in a certain area can act as interpreters. Sometimes, there is one dominant foreign language. In other areas, there are 120 different languages co-existing. The fire services state that they themselves cannot always reach the community residents, due to language barriers.

\section{A problem was also that everybody believed the entire block was going to burn to the ground. Everybody who lives there ran to their balconies and were about to jump because they thought they were going to die. There were huge problems and no interpreter in place, no one from the fire station.... (volunteer, central municipality, interview)}

Having relevant, knowledge of the area and knowing the people who live there is also central. The fire services claim that the volunteers are often more successful than the police in terms of outcomes, when backing crowds of people or explaining to them that there is, e.g., a cancer risk coming from smoke.

In the smaller municipality areas, the major perceived benefit is response time. The fire services claim that the effect here is directly related to the time factor because the civil volunteers almost always reach the emergency site before the professional response organizations.

\section{F. Challenges}

The major perceived challenge in the excluded central areas has been ensuring that the citizen volunteers actually respond 
to alerts and go to the incident site. Massive interest in recruitment is not the same thing as actually patrolling the neighborhood or taking action. During the first year, there were only a few enthusiasts who responded to many alerts, making first response an individual task. A related challenge concerns gender aspects. Many women did initially express interest. However, one year later, all the active volunteers were men and the fire services express uncertainty about how a female volunteer would be seen. In parts of the municipality dominated by Swedish ethnicity, male and female volunteers are about equal in numbers. Since the deliberate information campaigns were launched an increasing number of volunteers, including a few immigrant women, have received training. A steadily increasing number of volunteers are also becoming active in the system, acting on alerts. Nevertheless, activity in the FB groups is generally lower than for the smaller communities. The challenge to make first response a collective task thus remains:

I have always been on my own on a volunteer assignment. I know there is one volunteer active in XXX...I do not know if I should go on the alerts there too. It would be beneficial if there are several volunteers. For instance, one who talks to victims and one who directs the traffic. (volunteer, central municipality, interview)

Somewhat ironically, the challenges have been the other way around in the communities of mostly Swedish ethnicity. The engagement has been great from the beginning and there are currently so many active volunteers acting simultaneously on alerts that it sometimes causes problems for the professional response organizations when reaching the incident site:

\begin{abstract}
When we were at the electric fire. Then the fire chief said it was damn lucky that we were not 15 people. Then where would we put all the cars? There are both benefits and disadvantages when you have numerous volunteers showing up. (volunteer, small community, focus group)
\end{abstract}

Another perceived challenge in the central areas is, again, language. It is not optimal to send any volunteer, but rather one who knows the particular language of the victims involved in an emergency or the dominant language in the given sub-area. An explicit challenge in all areas is potential exposure to danger and crime is also on the increase in more remote communities:

\begin{abstract}
$X$ is like the wild west. Robberies every day. It is a disadvantage that they have the commuter train. Gangs from $Y$ and $Z$ come here. That's why I think maybe you should not run to a car on fire... at three o'clock in the morning...this night it was a tow trucker who was beaten up and robbed... (volunteer, small community, focus group)
\end{abstract}

Challenges also relate to the current app solution. The alerts sometimes arrive with some delay (thus counteracting the aim of a fast response). It has also happened occasionally that the office back-end system operators have sent alerts to volunteers that they should not have, e.g., a suicide alert. Another problem is the costs associated with the app. Municipal rescue services do not usually have strong financial resources, especially if they are small, and the supplier needs some return on investment.

\section{G. Needs and Requirements: Calibrating the ICT artifact}

The major need identified in the central part of the municipality, from the perspectives of both the fire-service respondents (focus group) and the volunteers (interviews), has been to have more volunteers acting as first responders, making it locality-based rather than individual-based. Apart from this, the citizen volunteers in the area did not express many general needs. One of them mentioned a warmer jacket and that exercises (recurring training) are good.

In contrast, the volunteers in the small community not only mention numerous needs but also sometimes propose their own solutions or have even bought their own materials. Examples of needs and requirements are jackets instead of vests, belt bags instead of backpacks, two powder extinguishers instead of one, and flashlights. They have bought "red pucks" and full light statuses for directing the traffic, at their own expense.

Concrete needs, however, in both areas, concern the current ICT solution. While the rescue services claim that using the commercial app has improved the effective response (in the initial phases they used SMS lists) in that they can reach the volunteers with information, and communicate with them, the volunteers in the central municipality mentioned that they sometimes receive the incorrect address/road coordinates from the rescue services back-office systems, thus delaying response time. They request an extended app version that includes an inbuilt GPS guidance system functionality. The fire services in the focus group also emphasize that that some matching functionality is increasingly needed with the initiative's progress, to send the "right" volunteer to the "right" site, identifying different roles, competences, and, in the central municipality, language groups. The volunteers in both areas have also requested more detailed and calibrated information in the app. They exemplify with information concerning the type of emergency, e.g., whether it is an electric or petrol-engine car that is burning (focus group). Now, they often call the rescue services for additional information. In the central municipality, examples concern which response organization has been called out, because this affects response times:

I would like the alert to provide more detailed
information... want to know if it is the rescue services from
$X X X$ and/or an ambulance from $Y Y Y$ that is arriving. If it
comes from $X X X$, it will take time. Damned important that I
am there in time. (volunteer, central municipality, interview)

\section{DISCUSSION}

Firstly, we discuss digitalized co-production, and ICT as an enabler; then how the knowledge gained from local initiatives can be transferred to national and international contexts.

\section{A. Digitalized Co-production: Opportunities and Barriers}

Initiatives directed specifically towards co-production are transforming our society at a global level [2],[28]. Coproduction is also increasingly associated with digitalization (e.g. [3], [3]), where many studies on citizen engagement in cities/urban areas, often have a a focus on smart cities, open data, and innovation, in well-off communities where 
sophisticated technologies are available (e.g. [7], [8]. As argued by [23], most studies look at how ICT can support and enable co-production (e.g. [3], [29]. Few focuses explicitly on their direct relation and on the ICT artefact itself as a catalyst of coproduction. Moving on to inclusion there are studies claiming that co-production can open up space for poor communities to work with their local governments in service delivery [30]. Others argue that security in these areas is not delivered by the police or an authoritarian attitude but is rather the co-product of relationships and collaboration [14]. Socio-economic gaps are expanding rapidly world-wide. Sweden is a typical example. The country took many immigrants during the refugee streams of 2015-2016 and is currently struggling to provide them with opportunities for integration. When searching the coproduction literature from 2016-2020, we found very few studies on this phenomenon in relation to digitalized coproduction, and specifically regarding emergency response. Thus, we believe that the studied initiative provides an interesting example in that it connects experiences from a western society to digitalization - not through sophisticated technology labs but instead through rather basic, easily accessible mobile ICT as a catalyst for co-production.

In the studied initiative, co-production has already contributed to faster response times and even to saving lives. At the same time, the challenges differ between different parts of the community, including degree of activity in the coproduction initiative and in related development of the ICT artifact. This reflects previous research related to using volunteers in remote areas of northern Sweden where the volunteers were also collectively engaged in co-production and active in the user participation process, even implementing their own ICT functions [31]. [14] has similar findings, claiming those in lower socio-economic situations, are less willing to participate in co-production, and fears that this will strengthen inequality between such residents and citizens living in wealthier areas. In relation, [23] showed that, even when collective insurance is provided, volunteers are not sufficiently protected by the current Swedish legal system. In light of this study, it seems crucial to address policy and liability issues in areas exposed to risks due to high rates of criminality, and this may influence citizen volunteer engagement in a positive way.

Somewhat ironically, even though the general challenges often contrast, they require the same functionality for future ICT artefacts. The initiative is broad but the ICT artefact, even though it is only a basic app, plays a central role in it. It seems to work sufficiently well in most cases, even though several improvements have been requested. However, the data analysis indicates that, for the initiative to be long term successful and to expand, the future design of the ICT artefact will contribute significantly. Future app solutions should add functions that allow for calibration/dynamic resource dispatching matching incident, competence, equipment, training, vehicles etc. In the city suburbs, language match seems a crucial factor, while in more remote communities dynamic resource allocation should be accompanied by an alert strategy, dispatching a pre-defined number of volunteers to different types of emergencies. If they do not respond, it should alert others in descending order. Also, a more secure solution, with a function allowing for withdrawal if an emergency should turn into something that is dangerous to the volunteers or if they arrive at emergency sites at which they should never have been present in the first place, is needed. This may also reduce fear about responding to an alert and stimulate long-term engagement in the excluded urban areas.

There is also a corresponding need for a thorough analysis of the necessary features and interfaces in the fire services' backoffice systems which provide the information to volunteers. Here, the overall infrastructure needs to be supervised. Service design can be divided into two parts: the service-providing process and the service-supporting process [32]. Paying attention to both these, including giving correct information to mobile solutions that have attractive, easy-to-handle interfaces, and offering improved communication between the fire services and volunteers, may also contribute to more volunteers acting on the alerts in urban areas.

\section{B. Transferring Local Co-production Experience}

The past decade's studies on engaging citizens in coproduction usually stem from public-administration and management research, often taking a macro, policy, governmental, and/or institutional perspective, also when digitalization is involved. This includes studies looking at how the technology has the potential to make co-production a common practice for all citizens, changing how services are delivered on a large scale, increasing public value, and inducing structural changes in public administration (e.g. [4, 33]). Also, [34] argue that more research is needed on how city neighborhoods, social capital, and status affect the willingness to engage in co-production. In this study, we aimed to start filling this gap, by focusing on an initiative that is not governmental but based on the efforts of a local municipal fire association and where a basic ICT artefact is a clear driver behind the co-production.

So, is it possible to use local experiences to influence and transform regional and national structures? In Swedish emergency response, this is in fact currently taking place. The concept of using citizen volunteers as first responders first emerged almost a decade ago in small, remote villages in northern Sweden [23]. The initiatives were totally based within the local municipality, sometimes with a single fire chief behind them. The idea spread through networks for the exchange of experience, and systematized knowledge transfer to other municipalities and, finally, to cities and excluded areas. We have participated actively in this work. Currently, the Swedish Civil Contingencies Agency (MSB), a state authority under the Swedish government, is working to transfer this knowledgebase to concepts to be widely implemented.

As regards potential for international knowledge transfer as to digitalized co-production, Sweden is deemed progressive for using volunteers in daily emergency response. We acknowledge that this is a case study based on a limited number 
of respondents and that the sampling strategy may have affected the study results, i.e., those most active in the initiative may also have been the ones to engage in the study. However, it is also our experience from earlier studies in rural areas that the engagement of volunteers there is generally high, and basic needs and challenges similar [23], [31]. The experiences from this study seem most relevant to countries that have similar legislation and a decentralized emergency response system. Nevertheless, we know that volunteerism in emergency response is rapidly increasing globally. Many basic needs relating to, e.g., motivation, training, equipment, and the design of the ICT artefact, should be similar. At the same time, it is admitted that Sweden is wealthy western country and that the results may not be entirely replicable, e.g., in countries where the ICT infrastructure is less developed. The studied case is of course most relevant to emergency response. However, other areas of application, based on citizens moving around in society and having easy access to mobile ICT, may also be relevant, e.g., in relation to healthcare and care of the elderly.

From a wider, public-sector perspective, the bi-directional influence of technology and various forms of governance has been recognized for over a decade [35], [36]. Several recent studies have claimed the need for a cross-fertilization of policy science and IS research perspectives, relating to emerging forms of government in an era of digitalization [19], [20], [21]. From this study, co-production can be seen as a typical instantiation and example where the disciplines may be used complementary, in both theory and practice. At the theoretical level, it is possible to argue that digitalization or an ICT artifact cannot be disregarded as an explicit part of most future coproduction initiatives and might thus be viewed as a point of departure, rather than as a support or enabler. At a practical level co-production is often related to co-creation [11]. Cocreation, in turn, has become something of a (rather fuzzy) buzzword, not least in urban governance, and often for the purpose of including and empowering marginalized groups [37]. Corresponding IS development approaches rely on the active participation of users, when developing both the ICT artefacts and the surrounding infrastructure [38]. In relation to IS research, equivalent approaches to co-creation but from a design perspective include e.g. participatory design (PD), and user-centered design. In particular, PD, which has clear political and ideological roots, has been applied to provide excluded societal groups with an opportunity to influence their own situation and environment, e.g., in urban planning [39]. In these design approaches, IS or an ICT artefact is generally a presumption, even though PD is also used in other contexts. A relevant research theme is thus: are there really differences between the various perspectives (e.g. co-creation versus PD), and if so, what are those differences?

\section{CONCLUSIONS AND FUTURE WORK}

We conclude that volunteer first responders with basic equipment and training can make a significant difference if they arrive first at an emergency site. However, the challenges and needs identified in the study must be addressed should this type of digitalized co-production expand. Here we see the potential for this study's results to be used as inspiration for emerging digitalized co-production initiatives. For excluded areas, a conclusion is that co-productions need more time and resources to strive than in more well-off areas but if this investment takes place, identified benefits will have great possibility to realize. At a theoretical macro-level, we perceive the need to mix research perspectives and relate it to the [33] claim that coproduction is at a crossroads. Thus, we argue for a digitalized perspective whereby future co-production initiatives explicitly include the ICT as a starting point.

As for future work, the results' transferability, to similar digitalized co-production contexts should be explored through more (case) studies. It has also been argued that studies on citizen co-production tend to focus almost exclusively on the objectives and influential factors of processes, and future research should thus include a more emphasized focus on the outcomes [40]. In line with this claim, both qualitative and quantitative variables have been identified and are integrated into the app solution. Quantitative data is currently gathered for a separate evaluation study, looking into number of volunteers in the system at a specific alert, how they react to it, and, if they actually show up at the emergency site. Also, since long-term engagement seems more challenging in the urban and/or socially vulnerable areas, we believe it is important to develop steering models and anchor with the municipalities, the rescue services, and the social services. It would also be beneficial to identify "driving spirits" and technology champions among the citizen volunteers, that can lead and motivate others. The gender aspect is also a future research trait, where we will need to integrate perspectives from sociology, ethnicity, and gender studies, if women are to become active in the urban areas. Finally, future ICT artefact solutions should handle the interface between the app and the back-office systems to hinder the volunteers to receive alerts that are not meant for them (e.g. suicide). The possibility to develop a joint national API for various app solutions are currently being discussed.

In the general context of public-sector digitalized transformation, we will carry out conceptual studies of how various research disciplines, theories, and practices relate to, synergize and can enrich each other in the fields of coproduction, and IS research, and in co-creation, versus userparticipation-based design approaches. Also, being able to use the same volunteers in daily emergency response and largescale crises would be beneficial because these volunteers would be accustomed to the ICT solutions, tasks, and work procedures. In Sweden, the government is currently planning for the large-scale digitalized coordination of volunteers, in the aftermath of the widespread forest wildfires of 2018. At a global level volunteerism is currently an essential part of handling the ongoing Corona-virus pandemic. Future research could thus focus on this dual use of volunteers.

\section{ACKNOWLEDGMENT}

This study was made possible by funding from Brandforsk and the Swedish Civil Contingencies Agency (MSB) 


\section{REFERENCES}

[1] F. Bannister and R. Connolly, "Trust and transformational government: a proposed framework for research", Government Information Quarterly, Vol. 28, No. 4, , 2011, pp. 137-147.

[2] E. Ostrom, "Crossing the great divide: coproduction, synergy, and development", World Development, Vol. 24, No. 6, 2016, pp. 10731087.

[3] V. Lember, T. Brandsen and P. Tonurist, "The potential impacts of digital technologies on co-production and co-creation", Public Management Review, Vol. 21, No. 11, 2019, pp. 1665-1686.

[4] A. Paletti, "Co-production through ICT in the public sector: when citizens reframe the production of public services ", Lecture Notes in Information Systems and Organisation, Vol. 18, Springer, Cham, 2016, pp. $141-152$.

[5] A. Purwanto, A. .Zuiderwijk, and M. Janssen, "Citizen engagement with open government data: lessons learned from Indonesia's presidential election", Transforming Government: People, Process and Policy, Vol. 14, No. 1, 2020, pp. 1-30.

[6] B. Granier, and H. Kudo, "How are citizens involved in smart cities? Analysing citizen participation in Japanese 'smart communities', Information Policy, Vol.20, No.1, 2016, pp. 61-76.

[7] A. Whicher and A. Crick, "Co-design, evaluation and the Northern Ireland Innovation Lab", Public Money and Management, Vol. 39, No. 4, 2019, pp. 290-299.

[8] W. Castelnovo, "Co-production makes cities smarter: citizens' participation in smart city initiatives", in M. Fugini, E. Bracci, and M. Sicilia, Eds. Co-production in the Public Sector, SpringerBriefs in Applied Sciences and Technology, Springer, Cham, 2016, pp. 97-117

[9] N. Guldåker and P-O. Hallin, "Spatio-temporal patterns of intentional fires, social stress and socio-economic determinants: a case study of Malmö, Sweden, ” Fire Safety Journal, Vol. 70, 2014, pp. 71-80.

[10] A. Chalfin and J. McCrary, "Criminal deterrence: a review of the literature", Journal of Economic Literature, Vol. 55, No.1, 2017, pp. 548.

[11] J. Alford and J. O'Flynn, Rethinking Public Service Delivery: Managing with External providers. Hampshire, UK: Palgrave Macmillan, 2012.

[12] V. Marino. and L. Presti, "From citizens to partners: the role of social media content in fostering citizen engagement", Transforming Government: People, Process and Policy, Vol. 12, No. 1, 2018, pp. 3960.

[13] H. Hedestig, D. Skog, and M. Söderström, "Co-producing public value through IoT and social media", in Proceedings of the 19th Annual International Conference on Digital Government Research: Governance in the Data Age., Vol. 22, Delft, Netherlands, May 2018, pp. 1-10.

[14] B. Holmes, "Citizens' engagement in policymaking and the design of public services", Department of Parliamentary Services Research Papers, Vol. 1, 2011, pp. 1-64.

[15] D. Vanleene, J. Voets, and B. Verschuere, "The co-production of a community: engaging citizens in derelict neighbourhoods", Voluntas, Vol. 29, 2018, pp. 201-221.

[16] S. Park, "Beyond patient-centred care: a conceptual framework of coproduction mechanisms with vulnerable groups in health and social service settings", Public Management Review, Vol. 22, No. 3, 2020, pp. 452-474.

[17] A. Allen, A. Walnycki, and É. von Bertrab, "The co-production of water justice in Latin American cities", in A. Allen, L. Griffin, and C. Johnson, Eds. Environmental Justice and Urban Resilience in the Global South, New York: Palgrave Macmillan, 2017, pp. 175-193.

[18] D. Cepiku and F. Giordano, "Co-production in developing countries: insights from the community health workers experience", Public Management Review, Vol. 16, No. 3, 2014, pp. 317-340.

[19] J. R. Gil-Garcia, S. S. Dawes, and T. A. Pardo, "Digital government and public management research: finding the crossroads," Public Management Review, Vol. 20, No. 5, 2018, pp. 633-646.

[20] U. Melin and E. Wihlborg, "Balanced and integrated e-government implementation: exploring the crossroad of public policy-making and information systems project management processes”, Transforming Government: People, Process and Policy, Vol. 12, No. 2, 2018, pp. 191208.

[21] T. Janowski, T. A. Pardo, and J. Davie., "Government information networks: mapping electronic governance cases through public administration", Government Information Quarterly, Vol. 29, No. 1, 2012, pp. 1-10.

[22] P. Díaz, J. M. Carroll, and I. Aedo, "Coproduction as an approach to technology-mediated citizen participation in emergency management", Future Internet, 2016, Vol. 8, No. 3, pp. 41.

[23] E. Ramsell, S. Pilemalm and T. Andersson Granberg, "Using Volunteers for Emergency Response in Rural Areas: Network Collaboration Factors and IT support in the Case of Enhanced Neighbors", in Proceedings of the 14th International Conference on Information Systems for Crisis Response and Management, Albi, 2017, pp. 985-995.

[24] B. Flyvbjerg, "Five misunderstandings about case-study research", Qualitative Inquiry, Vol. 12, No. 2, 2006, pp. 219-245.

[25] M. Myers, Qualitative Research in Business and Management. Thousand Oaks, CA: Sage Publications, 2009.

[26] S. Pilemalm, "ICT-Enabled Citizen Co-production in Excluded Areas - Using Volunteers in Emergency Response", in Electronic Participation. ePart, Lecture Notes in Computer Science, Vol. 11686, Springer, Cham, San Benedetto del Tronto, Italy, September 2019, pp 87-101.

[27] The Swedish Civil Protection Act (LOS 2003: 778).

[28] A. L. Ostrom, et al , "Moving forward and making a difference: research priorities for the science of service", Journal of Service Research, Vol. 13, No. 1, 2013, pp. 4-36.

[29] V. Verschuere, T. Brandsen, and V. Pestoff, "Co-production: the state of the art in research and the future agenda ", VOLUNTAS: International Journal of Voluntary and Non-profit Organisations, Vol. 23 No. 4, 2012, pp. 1083-1101.

[30] S. Boonyabancha and T. Keerr, "Lessons from CODI on co-production," Environment and Urbanization, Vol. 30, No. 2, 2018, pp. 1044-1056.

[31] E. Ramsell, S. Pilemalm and T. Andersson Granberg, "Identifying functions for smartphone based applications in volunteer emergency response", in Proceedings of the 16th International Conference on Information Systems for Crisis Response and Management, Valencia, Spain, May 2019, pp. 985-995.

[32] R. Kling, G. McKim, and A. King, "A bit more to IT: scholarly communication forums as socio-technical interaction networks, "Journal of the American Society for Information Science and Technology, Vol. 54, No. 1, 2003, pp. 47-67.

[33] T. Brandsen, T. Steen, and T. Verschuere, Eds. Co-Production and CoCreation: Engaging Citizens in Public Services. UK: Routledge, 2018.

[34] P. Thijssen and W. van Dooren, "Who you are/where you live: do neighborhood characteristics explain co-production?", International Review of Administrative Sciences, Vol. 82, No. 1, 2015, pp. 88-109.

[35] E. Loukis, M. Janssen, S. Dawes, and L. Zheng, "Evolving ICT and governance in organizational networks: conceptual and theoretical foundations”, Electronic Markets, Vol. 26, No. 1, 2016, pp. 7-14.

[36] S. Shan, L. Wang, and L. Li, "Modeling of emergency response decisionmaking process using stochastic petri net: an e-service perspective", Information Technology and Management, Vol. 13, No. 4, 2012, pp, 363376.

[37] D. Hedenstad Lund, "Co-creation in urban governance: from inclusion to innovation", Scandinavian Journal of Public Administration, Vol. 22, No. 2, 2018.

[38] P. Hillgren, A. Seravalli, and A. Emilson, "Prototyping and infrastructuring in design for social innovation", CoDesign, Vol. 7, No. 3-4, 2011, pp. 169-183.

[39] K. Halskov and N. B. Brodersen Hansen, "The diversity of participatory design research practice at PDC 2002-2012", International Journal of Human-Computer Studies, Vol. 74, 2015, pp. 81-92.

[40] W. H. Voorberg, V. J. J. M Bekkers., and L. G. Tummers, "A systematic review of co-creation and co-production: embarking on the social innovation journey", Public Administration Review, Vol. 17 No. 9, 2015, pp. 1333-1357. 